\title{
Use of rumination and activity monitoring for the identification of dairy cows with health disorders: Part II. Mastitis
}

\author{
M. L. Stangaferro, R. Wijma, L. S. Caixeta, ${ }^{1}$ M. A. Al-Abri, ${ }^{2}$ and J. O. Giordano ${ }^{3}$ \\ Department of Animal Science, Cornell University, Ithaca, NY 14853
}

\section{ABSTRACT}

The objectives of this study were to evaluate (1) the performance of an automated health-monitoring system (AHMS) to identify cows with mastitis based on an alert system (health index score, HIS) that combines rumination time and physical activity; (2) the number of days between the first HIS alert and clinical diagnosis (CD) of mastitis by farm personnel; and (3) the daily rumination time, physical activity, and HIS patterns around CD. Holstein cows ( $\mathrm{n}=1,121 ; 451$ nulliparous and 670 multiparous) were fitted with a neck-mounted electronic rumination and activity monitoring tag (HR Tags, SCR Dairy, Netanya, Israel.) from at least -21 to $80 \mathrm{~d}$ in milk (DIM). Raw data collected in 2-h periods were summarized per $24 \mathrm{~h}$ as daily rumination and activity. An HIS (0 to 100 arbitrary units) was calculated daily for individual cows with an algorithm that used rumination and activity. A positive HIS outcome was defined as an HIS of $<86$ units during at least $1 \mathrm{~d}$ from -5 to $2 \mathrm{~d}$ after CD. Blood concentrations of nonesterified fatty acids, $\beta$-hydroxybutyrate, total calcium, and haptoglobin were also determined in a subgroup of cows $(\mathrm{n}=459)$ at $-11 \pm 3,-4 \pm 3,0,3 \pm 1,7 \pm 1,14$ \pm 1 , and $28 \pm 1$ DIM. The sensitivity of the HIS was $58 \%$ [95\% confidence interval (CI): 49,67] for all cases of clinical mastitis $(\mathrm{n}=123)$, and $55 \%$ (95\% CI: 46, $64 ; \mathrm{n}=114)$ and $89 \%(95 \% \mathrm{CI}: 68,100 ; \mathrm{n}=9)$ for cases of mastitis alone or concurrent with other health disorders, respectively. Among clinical cases, sensitivity was $80.7 \%$ (95\% CI: 67, 97) for cases caused by Escherichia coli $(\mathrm{n}=31)$ and ranged from 45 to $48 \%$ for cases caused by gram-positive bacteria $(\mathrm{n}=39$; Streptococcus agalactiae, Streptococcus dysgalactiae, Streptococcus uberis, Streptococcus spp., Staphylococcus spp.,

\footnotetext{
Received January 18, 2016.

Accepted May 21, 2016.

${ }^{1}$ Current address: Department of Clinical Sciences, College of Veterinary Medicine and Biomedical Sciences, Colorado State University, Fort Collins, CO, 80523.

${ }^{2}$ Current address: Department of Animal and Veterinary Sciences, College of Agriculture and Marine Sciences, Sultan Qaboos University, Muscat, Sultanate of Oman.

${ }^{3}$ Corresponding author: jog25@cornell.edu
}

and Trueperella pyogenes), Staphylococcus aureus $(\mathrm{n}=$ $11)$, or cases with no bacterial growth $(\mathrm{n}=25)$. Days between the first HIS $<86$ and CD were -0.6 (95\% CI: $-1.1,-0.2)$ for all cases of mastitis. Cows diagnosed with mastitis had alterations of their rumination, activity, HIS patterns, and reduced milk production around $\mathrm{CD}$ depending on the type of mastitis case. Cows with mastitis also had some alterations of their calcium and haptoglobin concentrations around calving. The AHMS used in this study was effective for identifying cows with clinical cases of mastitis caused by E. coli and cows with another disease occurring during an event of mastitis, but it was less effective in identifying cows with mastitis not caused by $E$. coli.

Key words: rumination, activity, mastitis, dairy cow

\section{INTRODUCTION}

Early postpartum health disorders negatively affect cow well-being and are associated with significant economic losses for dairy farms because of alterations to cow health, welfare, and performance (Bareille et al., 2003; Ingvartsen, 2006; Hailemariam et al., 2014). Clinical mastitis is one of the most prevalent disorders affecting cow health and performance (Kaneene and Hurd, 1990; Ingvartsen et al., 2003; Østerås et al., 2007). Mastitis leads to major milk losses (Gröhn et al., 2004; Bar et al., 2007; Schukken et al., 2009) and reduces reproductive performance (Santos et al., 2004; Ahmadzadeh et al., 2009; Hertl et al., 2010); some types of mastitis may severely compromise cow health, leading to increased culling or death (Gröhn et al., 2005; Whist et al., 2009; Hertl et al., 2011).

To detect cows with clinical mastitis, health-monitoring programs include the evaluation of milk characteristics, signs of udder inflammation, and systemic signs of illness (Nash et al., 2002; Wenz et al., 2006). Cases of mastitis caused by certain pathogens such as Streptococcus agalactiae, Streptococcus dysgalactiae, and Streptococcus uberis are more commonly associated with mild changes in milk and udder inflammation (Todhunter et al., 1995; Keefe, 1997; Schukken et al., 2011); cases of mastitis caused by pathogens such as 
Escherichia coli and other gram-negative bacteria are characterized by a severe inflammatory response and systemic compromise (Harmon, 1994; Burvenich et al., 2007; Schukken et al., 2011). Thus, the severity of mastitis may range from mild changes in milk appearance to an important systemic compromise (Sargeant et al., 1998; Bradley and Green, 2001; Nikolić et al., 2003).

Multiple automated data collection systems based on sensors (e.g., daily milk weights, milk composition, electrical conductivity, somatic cell counts) have been tested and are available to detect mastitis through changes in milk production and its attributes (Kamphuis et al., 2008; Koop et al., 2015; Sørensen et al., 2016). Conversely, data about the use of automated rumination time and physical activity monitoring systems to detect cows with mastitis are scarce, because only a few studies have evaluated rumination time in cows with induced clinical mastitis or challenged with LPS (Siivonen et al., 2011; Fogsgaard et al., 2012; Fitzpatrick et al., 2013), and no studies have assessed a combination of both rumination and activity data to identify cows with mastitis. Beyond the potential of using rumination and activity monitoring alone or to complement other methods of mastitis detection, these 2 parameters may provide additional insights into overall cow health that are not provided by other sensor systems that monitor only milk or by clinical examination of cows and milk.

We hypothesized that an automated health-monitoring system (AHMS) that continuously monitors rumination and activity would be able to identify cows with mastitis. Also, we expected that changes in rumination and activity before evident clinical signs of disease would result in earlier identification of mastitis. The objectives of this study were to evaluate (1) the performance of an automated rumination and physical activity monitoring system to identify cows with mastitis; (2) the interval between the AHMS alert based on a health index score (HIS) and the day of clinical diagnosis (CD) by farm personnel; and (3) the rumination, activity, AHMS-generated alert, and milk production patterns for cows with mastitis. We also used markers of energy status [nonesterified fatty acids (NEFA) and $\mathrm{BHB}]$, mineral status (total calcium), and systemic inflammation (haptoglobin) were used to complement the diagnosis of mastitis and the performance of the AHMS alert.

\section{MATERIALS AND METHODS}

\section{Animals and Study Design}

All procedures were approved by the Institutional Animal Care and Use Committee of Cornell University.
The study followed an observational prospective cohort design. Details about the animals and study design are provided in a companion manuscript (Stangaferro et al., 2016). Briefly, Holstein cows ( $\mathrm{n}=1,121 ; 451$ nulliparous and 670 multiparous) were fitted with a neck-mounted electronic rumination and activity monitoring tag (HR Tags; SCR Dairy, Netanya, Israel) to monitor rumination and activity from at least $21 \mathrm{~d}$ before expected calving until at least $80 \mathrm{~d}$ after calving. Of 1,121 cows enrolled in the study, $41(3.7 \%)$ were removed from the data set due to tag malfunction or misplacement during data collection. Thus, 1,080 cows were included in the final data set for analysis. Based on rumination and activity data, an HIS (0 to 100 arbitrary units) for each cow was generated by the system software (DataFlow, Netanya, Israel) using a series of internal algorithms (proprietary to SCR Dairy). An HIS of 100 arbitrary units represents a cow with an ideal pattern of rumination and activity; an HIS value $<86$ arbitrary units may be indicative of a health disorder. An HIS report was generated daily to include cows with $<86$ arbitrary units (as determined by SCR) and stored for evaluation by the research group. During the study, farm personnel did not have access to the HIS report or any information generated by the AHMS.

\section{Fresh Cow Monitoring Program and Case Definitions}

The fresh cow health-monitoring program and definition of each particular health disorder are provided in detail in a companion manuscript (Stangaferro et al., 2016). In particular, clinical mastitis was defined as swelling or pain in the udder, or milk with abnormal appearance (milk was stripped onto the floor and observed for flakes or clots). Signs of udder inflammation may or may not have been accompanied by depressed attitude, anorexia, and fever. Mastitis monitoring was conducted during milking and during health monitoring of fresh cows. Milk culture was performed on all cows at the beginning of lactation (first milking) and on the day of mastitis diagnosis. Milk samples for pathogen detection were collected aseptically and shipped daily to the Quality Milk Production Services Laboratory at Cornell University (Ithaca, NY). Results were provided to the farm within $24 \mathrm{~h}$ of sample retrieval. Culture outcomes were grouped as follows: (1) E. coli; (2) Klebsiella spp.; (3) gram-positive bacteria (Strep. agalactiae, Strep. dysgalactiae, Strep. uberis, Streptococcus spp., Staphylococcus spp., Trueperella pyogenes); (4) Staphylococcus aureus; and (5) no important growth after $48 \mathrm{~h}$. Two consecutives episodes of mastitis were considered separate episodes if they occurred at least 7 $\mathrm{d}$ apart or in a different quarter. 


\section{Blood Collection and Laboratory Analyses}

Blood samples were collected from a subgroup of cows $(\mathrm{n}=459)$ on $\mathrm{d}-11 \pm 3$ and $-4 \pm 3$ prepartum, and $0,3 \pm 1,7 \pm 1,14 \pm 1$, and $28 \pm 1$ after calving. Plasma samples were analyzed for NEFA $(\mathrm{d}-11,-4$, $0,3,7,14,28)$, BHB (d 0, 3, 7, 14, 28), total Ca (d 0, 3, $7,14)$, and haptoglobin $(\mathrm{d}-4,0,3,7,14,28)$. Details about blood collection, plasma separation, and NEFA, $\mathrm{BHB}$, total $\mathrm{Ca}$ and haptoglobin analysis are provided in a companion manuscript (Stangaferro et al., 2016).

\section{Statistical Analysis}

System Performance. The main outcome of interest for this study was the ability of the HIS to correctly identify cows with mastitis. Clinical diagnosis by farm personnel was used as the reference test. Because HIS does not confirm the occurrence of disease or indicate the type of disease, a positive outcome was defined as an HIS value of $<86$ arbitrary units during at least $1 \mathrm{~d}$ during the $5 \mathrm{~d}$ preceding, the day of, or $2 \mathrm{~d}$ after $\mathrm{CD}$. The sensitivity and 95\% CI for the HIS to identify cows with mastitis was calculated using PROC FREQ in SAS (version 9.4; SAS Institute Inc., Cary, NC) and was defined as the ability of the HIS to correctly identify cows with a positive CD for mastitis. To evaluate the potential confounding effect of other health disorders (i.e., all disorders of interest, pneumonia, and lameness) on the sensitivity of HIS, we conducted 3 separate analyses. The first analysis included all cows with cases of clinical mastitis; a second analysis included cows diagnosed only with mastitis during the range of interest around $\mathrm{CD}$; and a third analysis included cows diagnosed with mastitis and at least one other health disorder during the range of interest around CD. Clinical cases of mastitis were also stratified by milk culture results. For this analysis, cows were separated into the following groups: (1) E. coli; (2) Klebsiella spp.; (3) gram-positive bacteria (Strep. agalactiae, Strep. dysgalactiae, Strep. uberis, Streptococcus spp., Staphylococcus spp., T. pyogenes); (4) Staph. aureus; and (5) no important growth after $48 \mathrm{~h}$. We determined differences in the sensitivity of HIS between the subgroup of cows with mastitis only and cows with mastitis and at least another disorder, and for the different pathogen subgroups, by logistic regression using the events over trials option of PROC LOGISTIC in SAS.

Interval Between the First Positive HIS Outcome and Clinical Diagnosis. To determine if HIS was capable of identifying cows with mastitis earlier than CD by farm personnel, the interval (in days) between the first positive HIS outcome during the period of interest around CD ( $5 \mathrm{~d}$ before to $2 \mathrm{~d}$ after) and the day of CD was evaluated. For this analysis, which included only cows flagged by the AHMS, we compared the mean number of days from the first HIS-positive outcome and the day of $\mathrm{CD}$ with a paired $t$-test conducted using the PROC TTEST in SAS.

Rumination, Activity, HIS, and Milk Production Relative to Clinical Diagnosis. Daily rumination time ( $\mathrm{min} / \mathrm{d})$, daily activity (arbitrary units/d), and HIS (arbitrary units) were evaluated from $5 \mathrm{~d}$ before to $5 \mathrm{~d}$ after $\mathrm{CD}(\mathrm{d} 0)$ for the first event of mastitis. Milk production $(\mathrm{kg} / \mathrm{d})$ was evaluated only from $5 \mathrm{~d}$ before until the day of $\mathrm{CD}$, because data was not available after CD for cows treated with an antibiotic that required milk withdrawal. Before statistical analysis, we assessed normality of the data for rumination, activity, HIS, and milk production using the Shapiro-Wilk statistic and graphical methods (histogram and Q-Q plot) and using PROC UNIVARIATE in SAS. Based on this analysis, no data transformations were necessary.

Different analyses were conducted using data from groups of cows created based on specific criteria. A first analysis included a nondisease group (ND) and the group with clinical mastitis (for first event of mastitis). Thereafter, cows were grouped according to the following criteria: CD-positive and HIS-positive (HI+; HIS $<86$ arbitrary units at least $1 \mathrm{~d}$ within $5 \mathrm{~d}$ before, the day of, and $2 \mathrm{~d}$ after $\mathrm{CD}$ ); CD-positive and HIS-negative (HI-; HIS $\geq 86$ arbitrary units from $5 \mathrm{~d}$ before, the day of, and $2 \mathrm{~d}$ after $\mathrm{CD}$ ); and CD-negative (ND; cows not diagnosed with a health disorder during the study period). For cows in the ND group, we considered the average DIM at CD for cows with mastitis "day 0." Data were analyzed by ANOVA with repeated measurements using PROC MIXED in SAS. Models for each outcome of interest included group (e.g., ND and clinical mastitis; and ND, HI+, and $\mathrm{HI}-$ ), time, and group-by-time interaction as explanatory variables. Parity and group-by-parity interaction were also offered to the initial models. The occurrence of another health disorder (i.e., all disorders of interest, pneumonia, and lameness) during the -5 to $5 \mathrm{~d}$ period after $\mathrm{CD}$ was offered as a categorical variable $(0=$ no occurrence and $1=$ occurrence) to the initial models to evaluate the potential effect of multiple disorders on the parameter of interest. The final model for each variable of interest was selected by backward elimination of explanatory variables with $P>0.10$ and determination of the lowest value for the Akaike's information criterion. Group, time, and group-by-time interaction were forced in all models. Cow within group was included as a random effect in all models. Cow was the subject of the repeated measurements, and all models were run using an autoregressive (AR-1) covariance structure. When the main effect or interaction between explanatory 
variables was significant, we used the LSD post hoc mean separation test to determine differences between groups of means.

Plasma Concentrations of NEFA, BHB, Ca, and Haptoglobin. Cows were grouped in the same way as for evaluation of rumination, activity, and HIS. Data were analyzed by ANOVA with repeated measurements using PROC MIXED in SAS as described and using the same models as for the other parameters.

Data for proportions are presented as arithmetical means and 95\% CI; quantitative data are presented as $\mathrm{LSM} \pm \mathrm{SEM}$ or $95 \% \mathrm{CI}$, unless otherwise stated. All explanatory variables and their interactions were considered significant if $P \leq 0.05$, and $0.05<P \leq 0.10$ was considered a tendency.

\section{RESULTS}

\section{Mastitis Incidence and System Performance}

The incidence of mastitis and DIM at CD are presented in Table 1. Of all the cows affected with clinical mastitis during the study period $(\mathrm{n}=123), 90.2 \%$ developed 1 event and $9.8 \%$ developed 2 events. The greatest incidence observed was for cases with a culture result for gram-positive bacteria (not including Staph. aureus), followed by E. coli and no growth after $48 \mathrm{~h}$. Eleven cows with clinical mastitis $(8.9 \%$ of the total clinical cases) were not included in the analysis for specific pathogens because they had the following culture results: yeast, no culture results, other, or contamination.

The sensitivity of HIS to detect cows with mastitis and the interval between an HIS-positive outcome and a CD of mastitis by farm personnel are also presented in Table 1. The overall sensitivity for clinical mastitis was $58 \%$, with a tendency to be greater $(P=0.08)$ for cows that developed another health disorder from -5 to $2 \mathrm{~d}$ after $\mathrm{CD}$ than for cows that had mastitis only (89 vs. $55 \%$, respectively). For cases of clinical mastitis stratified by pathogen, the sensitivity of HIS was greater $(P=0.04)$ for mastitis caused by $E$. coli $(81 \%)$ than for cases caused by Klebsiella spp. (33\%), gram-positive bacteria (49\%), Staph. aureus $(46 \%)$ or no growth after $48 \mathrm{~h}(48 \%)$. Overall, all cases of clinical mastitis were flagged earlier $(P<0.02)$ based on HIS than CD by farm personnel.

\section{Rumination, Activity, HIS, and Milk Production Relative to Clinical Diagnosis}

Daily rumination time, activity, and HIS patterns from -5 to $5 \mathrm{~d}$ after $\mathrm{CD}$ for cows with clinical mastitis
( $\mathrm{n}=110$; first event of mastitis only), and cows in the ND group $(\mathrm{n}=435)$ are shown in Figure 1. For all parameters, the effect of parity and the group-byparity interaction were not significant. For rumination, we observed an interaction between group and day $(P$ $<0.01)$. Rumination was lower for cows in the clinical mastitis group than for cows in the ND group from -1 to 3 d relative to CD. Cows with clinical mastitis reached their nadir $(\sim 397 \mathrm{~min} / \mathrm{d})$ on $\mathrm{d}-1$. We detected an interaction between group and day $(P<0.01)$ for activity. Cows with clinical mastitis had lower activity than cows in the ND group during the entire period analyzed, reaching their nadir ( $\sim 485$ arbitrary units $/ d)$ on $\mathrm{d} 0$. We observed an interaction between group and day $(P<0.01)$ for HIS in cows with mastitis. Cows in the clinical mastitis group had lower HIS than cows in the ND group from -1 to $5 \mathrm{~d}$ relative to CD, reaching the lowest value ( $\sim 84$ HIS units) on d 0 . In addition, HIS was affected by the occurrence of metritis. Cows with metritis had lower HIS $(P<0.01)$ than cows without metritis during the period of interest around CD $(88.3 \pm 1.7$ vs. $95.2 \pm 0.1$ units, respectively).

Figure 2 includes rumination, activity, and HIS patterns from -5 to $5 \mathrm{~d}$ relative to $\mathrm{CD}$ for cows with clinical mastitis caused by $E$. coli or gram-positive bacteria and included in the HI+ and HI- groups. For all parameters, the effect of parity and the groupby-parity interaction were not significant. For cows with mastitis caused by E. coli (Figure 2A, B, C), we observed an interaction between group and day $(P<$ $0.01)$ for rumination. Rumination times were lower for cows in the HI+ group $(\mathrm{n}=21)$ than the ND group $(\mathrm{n}=435)$ from -1 to $3 \mathrm{~d}$ relative to $\mathrm{CD}$, reaching their nadir $(\sim 291 \mathrm{~min} / \mathrm{d})$ and the greatest difference with the ND group $(\sim 183 \mathrm{~min} / \mathrm{d})$ on $\mathrm{d} 0$. Cows in the HI- group $(\mathrm{n}=5)$ had higher rumination time than cows in the $\mathrm{HI}+$ group from -1 to $1 \mathrm{~d}$ relative to $\mathrm{CD}$. We detected an interaction between group and day $(P$ $=0.01$ ) for activity. Cows in the HI+ group had lower activity than cows in the HI- and ND groups from -1 to $5 \mathrm{~d}$ relative to $\mathrm{CD}$. We detected an interaction between group and day $(P<0.01)$ for HIS, such that cows in the HI+ group had lower HIS than cows in the $\mathrm{HI}-$ and ND groups from 0 to 2 and from 0 to $3 \mathrm{~d}$ after $\mathrm{CD}$, respectively. The HIS for cows in the HI+ group reached their lowest value ( $\sim 77$ units) on the day of CD. In addition, HIS was affected by the occurrence of lameness, because cows with lameness had reduced HIS $(P<0.01)$ than cows without lameness during the period of interest around CD $(94.6 \pm 0.3$ vs. $99.6 \pm 1.8$ units, respectively).

For cows diagnosed with mastitis caused by grampositive bacteria (Figure 2D, E, F), we observed an 
RUMINATION AND ACTIVITY FOR HEALTH MONITORING

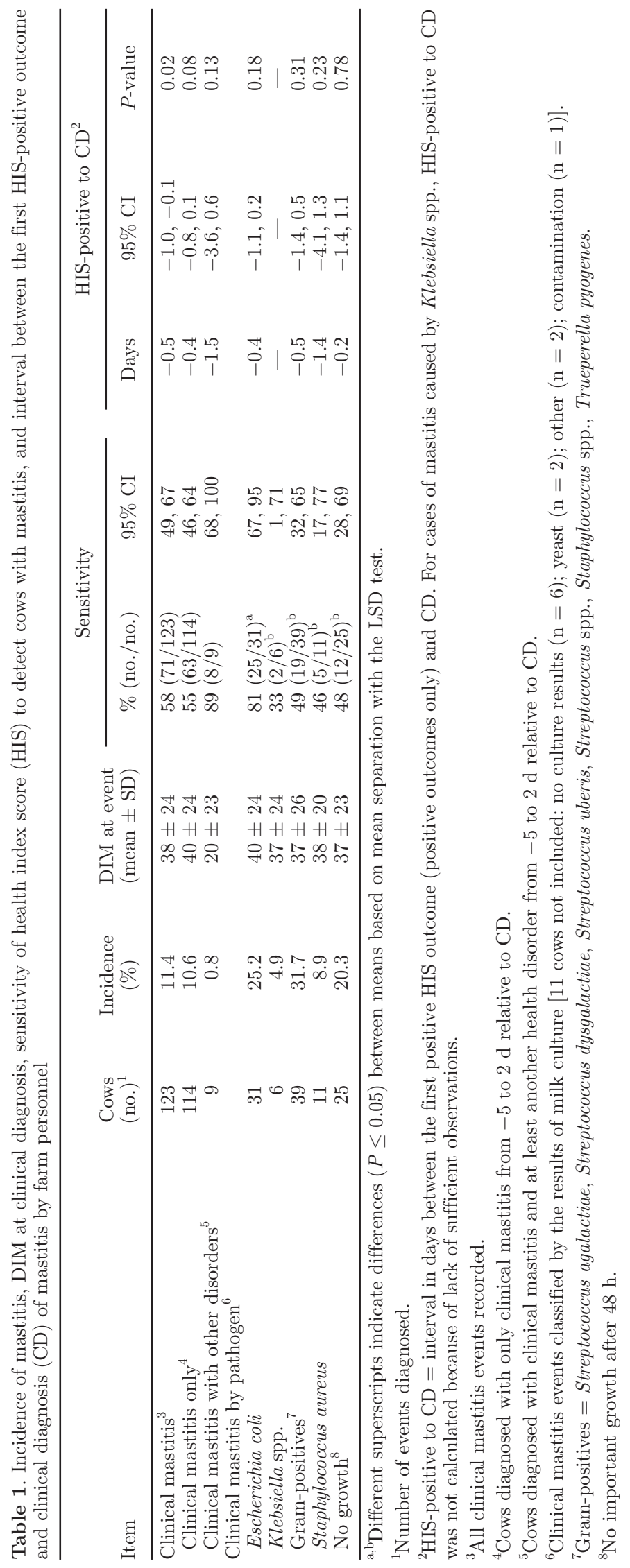



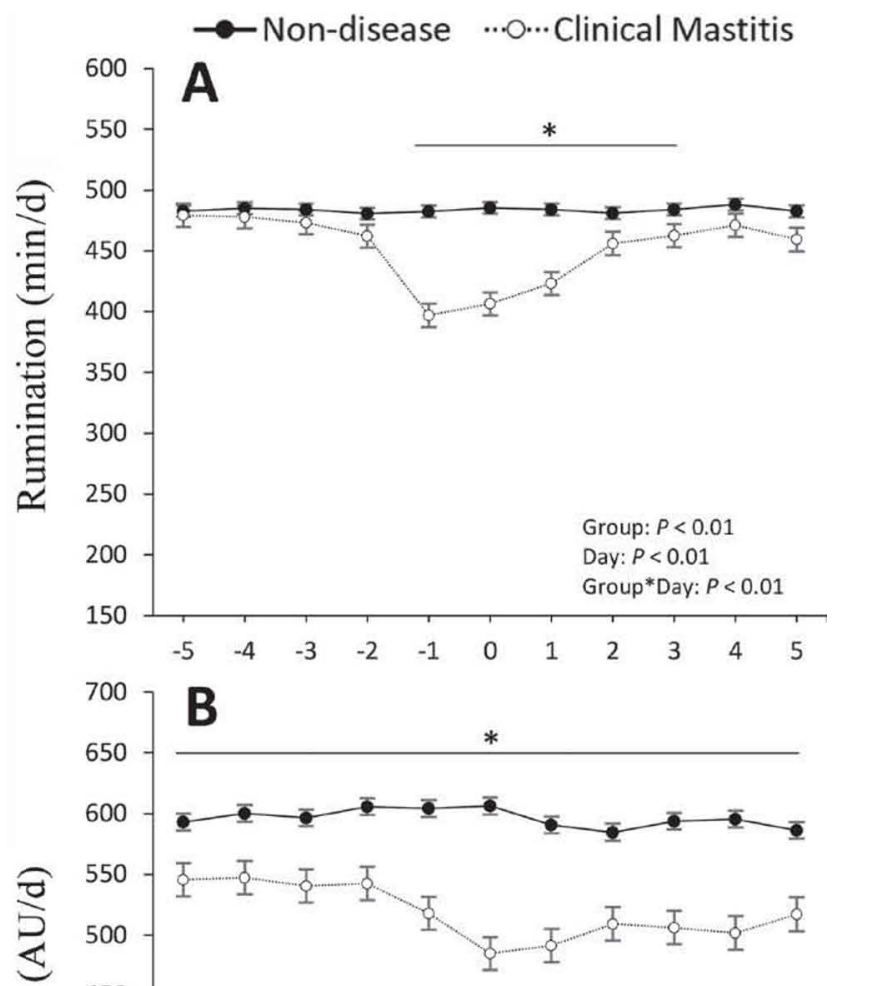

.

党
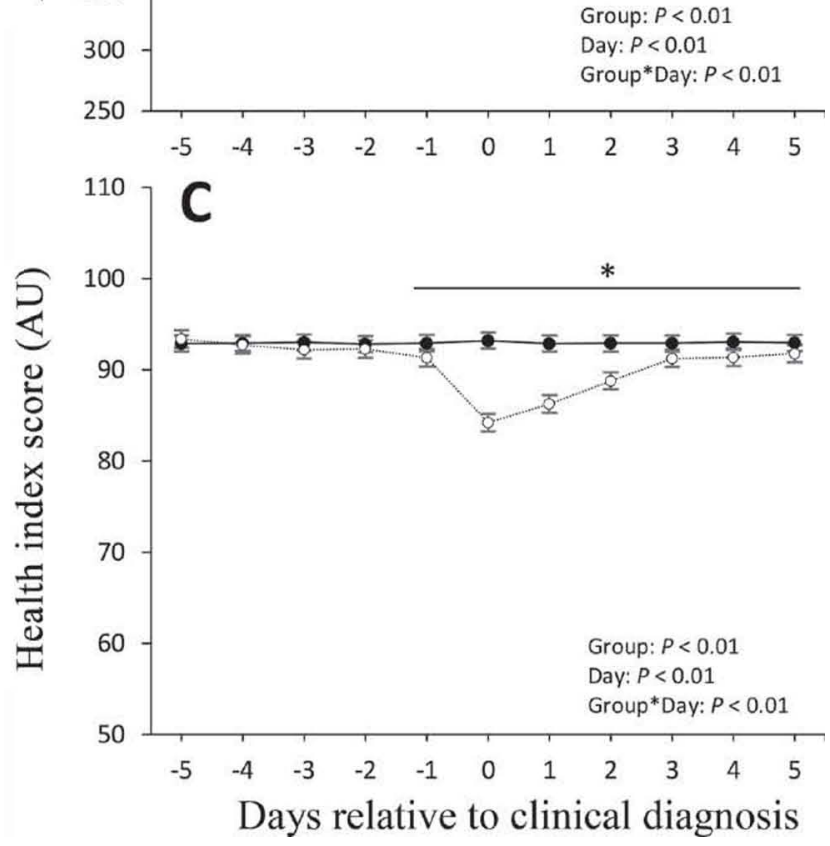

Figure 1. Rumination (A), activity (B; arbitrary units, AU), and health index score $(\mathrm{AU} ; \mathrm{C})$ patterns from -5 to $5 \mathrm{~d}$ relative to clinical diagnosis for cows that developed clinical mastitis (first event only; $\mathrm{n}$ $=110)$ compared with cows in the nondisease group $(\mathrm{n}=435)$. For the nondisease group, the average DIM at CD for cows with mastitis was considered "day 0." Values are presented as LSM \pm SEM. Within a day, differences $(P \leq 0.05)$ for pairwise comparisons between the nondisease and clinical mastitis group are represented by an asterisk $(*)$. interaction between group and day $(P<0.01)$ for rumination. Cows in the HI+ group $(\mathrm{n}=19)$ had lower rumination than cows in the ND $(\mathrm{n}=435)$ group from -1 to $4 \mathrm{~d}$ relative to $\mathrm{CD}$, reaching a nadir $(\sim 330$ $\mathrm{min} / \mathrm{d})$ on $\mathrm{d} 0$. Cows in the HI- group $(\mathrm{n}=23)$ had higher rumination than cows in the $\mathrm{HI}+$ group from 0 to $4 \mathrm{~d}$ after $\mathrm{CD}$. We detected an interaction between group and day $(P=0.05)$ for activity. Daily activity was lower in the HI+ group than in the ND group from -2 to $5 \mathrm{~d}$ relative to CD; cows in the HI- group exhibited no difference compared with the HI+ or ND groups. We detected an interaction between group and day $(P<0.01)$ for HIS. Cows in the HI+ group had lower HIS than cows in the HI- and ND groups from -2 to $5 \mathrm{~d}$ relative to $\mathrm{CD}$, with the lowest values $(\sim 86$ HIS units) from d 0 to 2 . In addition, HIS was also affected by the occurrence of metritis, because cows with metritis had reduced HIS $(P<0.01)$ than cows without metritis during the period of interest around CD (88.6 \pm 2.2 vs. $94.8 \pm 0.2$ units, respectively).

Daily milk production $(\mathrm{kg} / \mathrm{d})$ from 5 d before until the day of $\mathrm{CD}$ for cows that had clinical mastitis is presented in Figure 3. Because parity had an effect $(P$ $<0.01$ ) on milk production, results are presented separately for primiparous and multiparous cows. For primiparous cows (Figure 3A), we observed an interaction between group and day $(P<0.01)$. Cows with mastitis regardless of HIS group (HI+ and HI-) produced less milk than cows in the ND group from -3 to 0 (HI- vs. $\mathrm{ND})$ and from -2 to $0 \mathrm{~d}(\mathrm{HI}+$ vs. ND) relative to $\mathrm{CD}$. We observed the greatest difference between cows in the HI+ and ND groups on $\mathrm{d}-1(12.8 \mathrm{~kg} / \mathrm{d})$, and the greatest difference between cows in the HI- and in the ND group on d $0(9.5 \mathrm{~kg} / \mathrm{d})$. We observed no differences between primiparous cows in the HI+ and HI- groups. For multiparous cows (Figure 3B), we observed an interaction between group and day $(P<0.01)$. Multiparous cows in the HI+ and HI- groups produced less milk than cows in the ND group from $-2 \mathrm{~d}$ until the day of $\mathrm{CD}$. We observed the greatest difference between the $\mathrm{HI}+$ and $\mathrm{HI}-$ groups compared to the ND group on $\mathrm{d} 0(16.9 \mathrm{~kg} / \mathrm{d}$ and $10.1 \mathrm{~kg} / \mathrm{d}$, respectively $)$. Cows in the HI+ group produced less milk than cows in the HI- group on the day of CD.

\section{Plasma Concentrations of NEFA, BHB, Ca, and Haptoglobin}

Plasma concentrations of NEFA, BHB, Ca, and haptoglobin for cows that developed clinical mastitis before 30 DIM are presented in Figure 4. We detected only an effect of day $(P<0.01)$ for NEFA concentrations, because NEFA were greater on d 0,3 , and 7 than the rest of the days. We detected no effect of group $(P=0.58)$ 
or day $(P=0.64)$, and no interaction between group and day $(P=0.83)$ for $\mathrm{BHB}$ concentrations. For total Ca concentrations, we observed a group-by-day interac- tion $(P=0.03)$. Cows in the $\mathrm{HI}+$ group had lower $\mathrm{Ca}$ concentrations $(\sim 1.0 \mathrm{mg} / \mathrm{dL}$ different $)$ than cows in the $\mathrm{HI}-$ and ND group at 14 DIM. For haptoglobin concen-
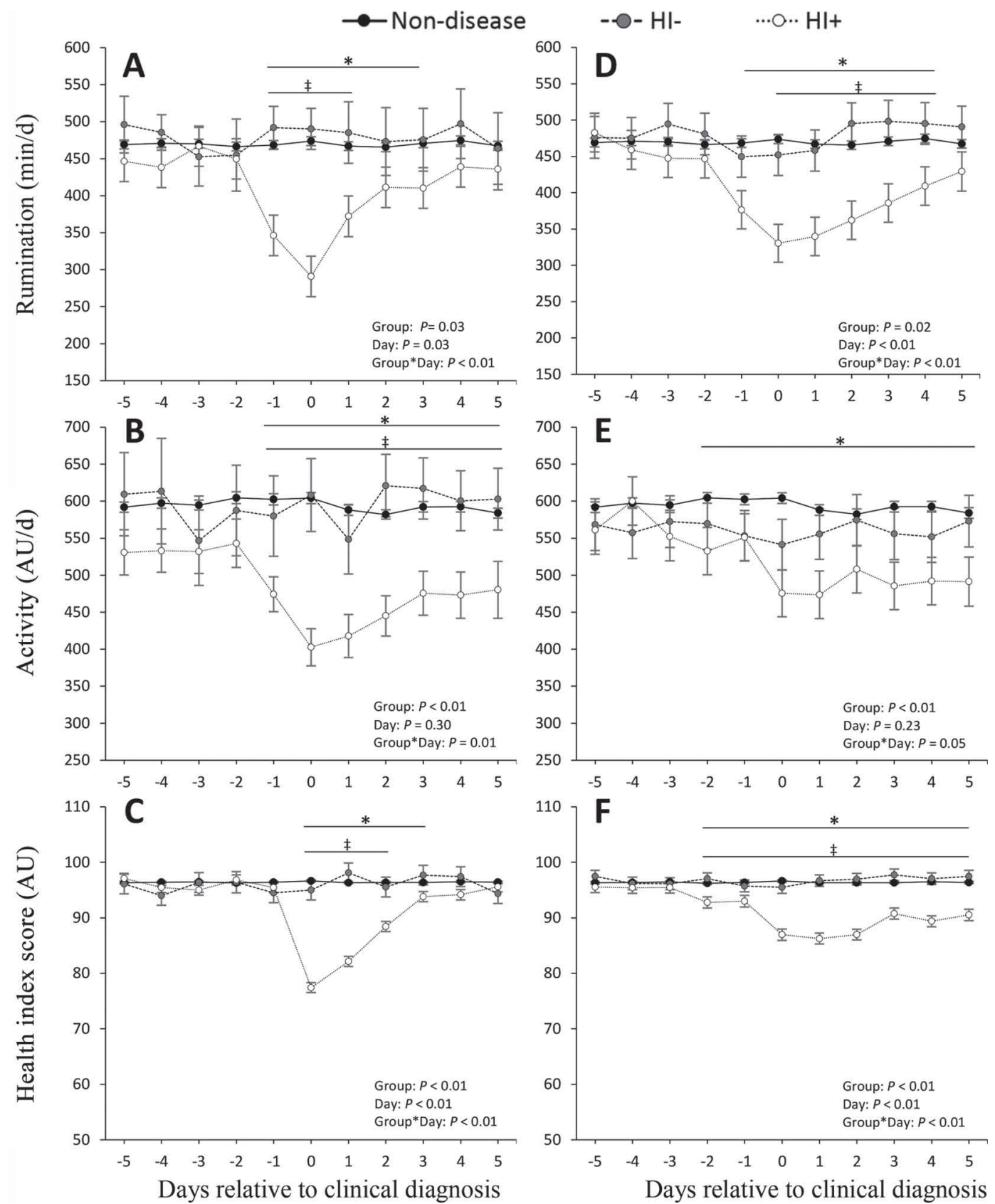

Figure 2. Rumination (A), activity (B ; arbitrary units, AU), and health index score (HIS, AU; C) patterns from -5 to 5 d relative to clinical diagnosis $(\mathrm{CD})$ for cows that developed clinical mastitis caused by Escherichia coli $(\mathrm{HI}+: \mathrm{n}=21 ; \mathrm{HI}-: \mathrm{n}=5)$ compared with cows in the nondisease group $(\mathrm{n}=435)$. Cows were assigned to the HI+ or HI- group if they had an HIS of $<86$ or $\geq 86$ arbitrary units, respectively, during the $5 \mathrm{~d}$ preceding, the day of, and $2 \mathrm{~d}$ after CD. For cows in the nondisease group, the average DIM at CD for cows with mastitis was considered "day 0." Rumination (D), activity (E), and HIS (F) patterns from -5 to 5 d relative to clinical diagnosis for cows that developed clinical mastitis caused by gram-positive bacteria (Streptococcus agalactiae, Streptococcus dysgalactiae, Streptococcus uberis, Streptococcus spp., Staphylococcus spp., Trueperella pyogenes) compared with cows in the nondisease group $(\mathrm{n}=435)$. Cows with clinical mastitis caused by grampositive bacteria were assigned to the HI $+(\mathrm{n}=19)$ and $\mathrm{HI}-(\mathrm{n}=18)$ groups following the same criteria as for cows with clinical mastitis caused by E. coli. Values are presented as LSM \pm SEM. Within a day, pairwise comparisons that were statistically different $(P \leq 0.05)$ based on LSD are represented as follows: ${ }^{*}$ control vs. HI+; $\ddagger \mathrm{HI}+$ vs. HI- 

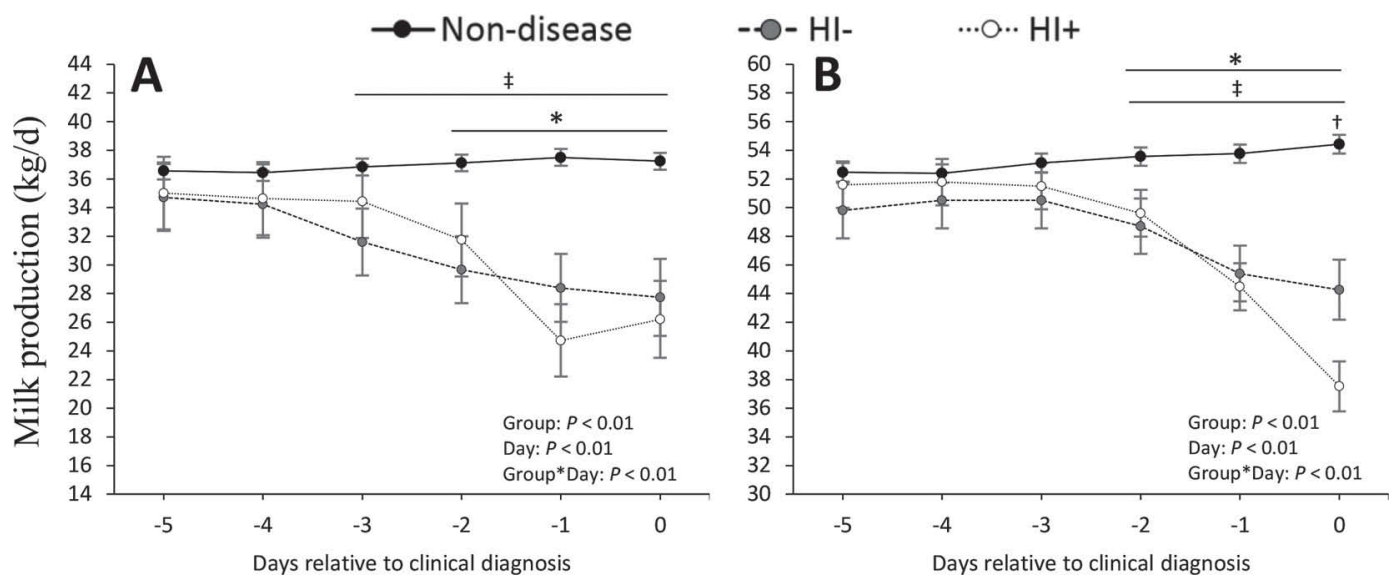

Figure 3. Milk production $(\mathrm{kg} / \mathrm{d})$ from $-5 \mathrm{~d}$ to the day of clinical diagnosis $(\mathrm{CD} ; \mathrm{d} 0)$ for primiparous cows (A) that developed clinical mastitis (HI+: $\mathrm{n}=15 ; \mathrm{HI}-: \mathrm{n}=12)$ compared with cows in the nondisease group $(\mathrm{n}=171)$. Cows were assigned to the HI+ or HI- group if they had a health index score of $<86$ or $\geq 86$ arbitrary units, respectively, during the $5 \mathrm{~d}$ before, the day of, and $2 \mathrm{~d}$ after clinical diagnosis. Milk production $(\mathrm{kg} / \mathrm{d})$ from $-5 \mathrm{~d}$ to the day of CD for multiparous cows (B) that developed clinical mastitis compared with cows that did not develop mastitis (nondisease; $\mathrm{n}=264)$. Multiparous cows with mastitis were assigned to the HI+ $(\mathrm{n}=49)$ and HI- $(\mathrm{n}=33)$ groups following the same criteria as for primiparous cows with mastitis. Values are presented as LSM \pm SEM. Within a day, pairwise comparisons that were statistically different $(P \leq 0.05)$ based on LSD are represented as follows: ${ }^{*}$ control vs. HI $+; \dagger$ control vs. HI-; $\ddagger$ HI + vs. HI-.

trations, we observed an interaction between group and day $(P=0.02)$. Cows with clinical mastitis (both $\mathrm{HI}+$ and HI- groups) had greater haptoglobin concentrations than cows in the ND group on d 14 and 28.
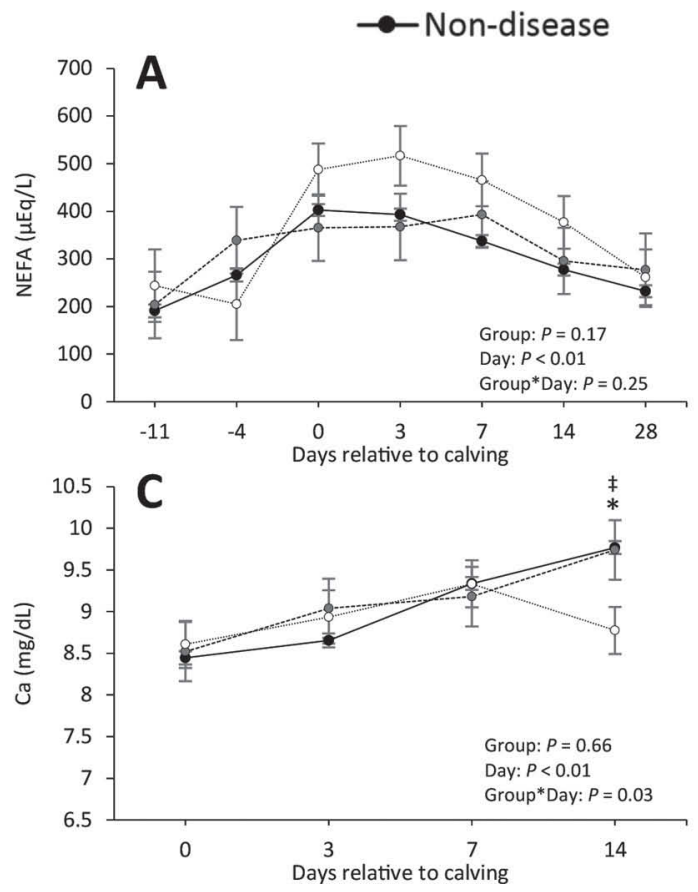

\section{DISCUSSION}

In the current study, we evaluated the performance an AHMS that combined rumination and activity to
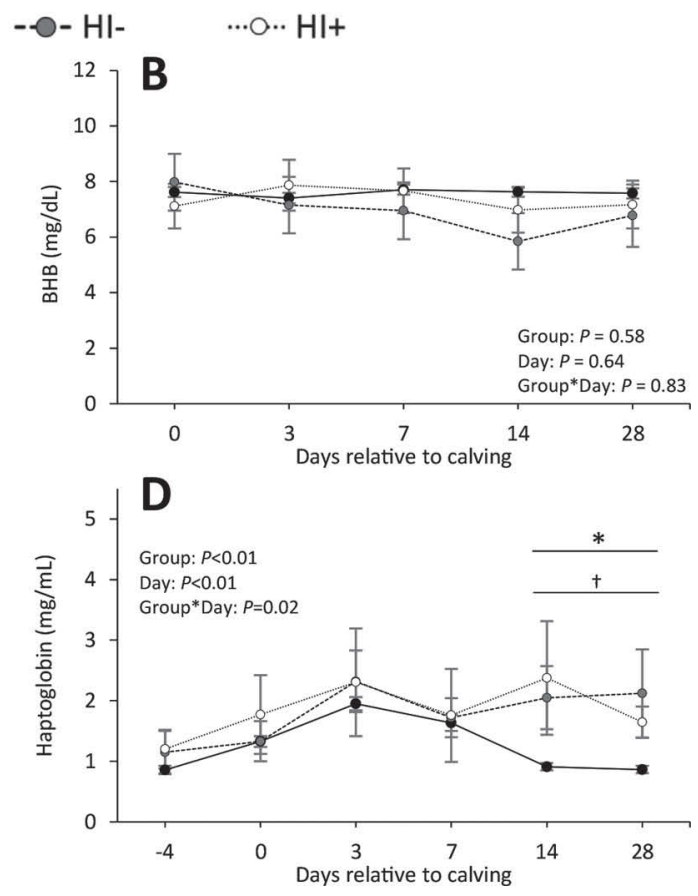

Figure 4. Plasma concentrations of nonesterified fatty acids (NEFA; A), BHB (B), total calcium (C), and haptoglobin (D) for cows that developed clinical mastitis up to $30 \mathrm{DIM}(\mathrm{HI}+\mathrm{n}=8$; HI-: $\mathrm{n}=5$ ) compared with cows in the nondisease group ( $\mathrm{n}=161$ ). Cows with mastitis were assigned to the HI+ or HI- group if they had a health index score of $<86$ or $\geq 86$ arbitrary units, respectively, during the $5 \mathrm{~d}$ preceding, the day of, and $2 \mathrm{~d}$ after clinical diagnosis. Values are presented as LSM \pm SEM. Within a day, pairwise comparisons that were statistically different $(P \leq 0.05)$ based on LSD are represented as follows: *control vs. HI+; †control vs. HI-; $\ddagger$ HI+ vs. HI-. 
identify cows with mastitis. Our results support the notion that an HIS alert generated based on rumination and activity would be able to identify cows with more severe cases of mastitis. We observed moderate sensitivity when all cases of mastitis were included in the analysis but substantial differences in sensitivity when cows were stratified based on the presence or absence of another disorder from $5 \mathrm{~d}$ before to $2 \mathrm{~d}$ after clinical diagnosis of mastitis. Moreover, when cows with mastitis caused by E. coli were evaluated individually, the sensitivity of the AHMS was more than 20 percentage points greater than when all cases were combined. This finding was expected, because intramammary infections caused by $E$. coli are characterized by a severe inflammatory response, including sudden shock, sepsis, and often death (Burvenich et al., 2003; 2007; White et al., 2010; Schukken et al., 2011). Indeed, cows affected by E. coli and identified by the AHMS (HI+ group) had sudden and dramatic reductions in rumination, activity, and HIS, reaching nadirs similar than those of cows affected by metabolic and digestive disorders (Stangaferro et al., 2016). As a result of the low HIS observed during the nadir ( $<86$ points), most cows were flagged by the AHMS. Conversely, the low sensitivity of the AHMS in detecting cows with mastitis caused by Klebsiella spp. was unexpected. Clinical cases caused by this pathogen are usually characterized by clinical signs similar to those observed in mastitis caused by E. coli (Harmon, 1994; Radostits et al., 2006). Although we did not have information about the severity of the mastitis event, we speculate that the moderate sensitivity of the AHMS in these cases was due to an over-representation of mild cases among the small number of cows with mastitis caused by this pathogen.

The observed lower sensitivity for cases of clinical mastitis caused by gram-positive pathogens and Staph. aureus was also expected, because these pathogens do not cause the same level of toxemia as E. coli (Harmon, 1994; Todhunter et al., 1995; Keefe, 1997; Schukken et al., 2011). Based on the patterns of rumination, activity, and HIS for the HI+ group, however, it seemed obvious that this subgroup contained cows with more severe cases of mastitis and systemic compromise. Cows in the HI+ group had significant reductions in rumination and activity within 1 to $2 \mathrm{~d}$ before $\mathrm{CD}$ and, for some cows, the HIS was below 86 points from the day of and up to $2 \mathrm{~d}$ after CD. It is uncertain whether the cases of clinical mastitis with no pathogen growth in cultured milk resembled more closely those caused by E. coli or the rest of the pathogens isolated during the study. However, the sensitivity of the AHMS for this subgroup of cows and the patterns of rumination, activity, and HIS (data not shown) closely matched those of cows with mastitis caused by gram-positive pathogens and Staph. aureus.

Another interesting aspect of cows affected by clinical mastitis was the lack of difference in milk production between cows in the HI+ and HI- groups around CD (except for d 0 in the multiparous group). Both groups produced less milk on the days leading up to and day of CD than cows with no health disorders. This was in contrast to our observations for metabolic and digestive disorders (Stangaferro et al., 2016). In such cases, milk production before CD was lowest for cows in the HI+ group; cows in the HI- group had less of a reduction or no reduction before CD compared to cows in the ND group. These contrasting results for milk production differences between the HI+ and HI- groups for cows affected by metabolic and digestive disorders or mastitis were probably a reflection of the reasons underlying reduced milk production. It is likely that in cows with clinical mastitis, the decline in milk production around $\mathrm{CD}$ was, for the most part, due to the direct effect of inflammation on the mammary gland (Zhao and Lacasse, 2008; Akers and Nickerson, 2011). In contrast, it is likely that cows with metabolic and digestive disorders produced less milk because of a reduction in DMI and the overall effect of disease on cow health (Bareille et al., 2003; Van Winden et al., 2003).

Similar to cows with metabolic and digestive disorders (Stangaferro et al., 2016), cows with clinical mastitis and an HIS $<86$ points were flagged earlier than by farm personnel (approximately half a day). In this case, the difference in favor of the AHMS was smaller than for the other disorders, and we observed no statistical differences when mastitis events were separated by pathogen. The short time frame from an HIS $<86$ points and CD was likely a reflection of the sudden drop in rumination and activity within no more than $1 \mathrm{~d}$ of CD in cows flagged based on HIS. In contrast, for disorders such as displaced abomasum or ketosis, rumination and activity were below levels observed in cows with no health disorders as early as $5 \mathrm{~d}$ before CD. Taken together, these results suggest that there may not be a major advantage for the AHMS in terms of the timing of mastitis diagnosis for herds with similar mastitis detection programs. The characteristic changes in milk composition, udder appearance, and consistency observed in cows with clinical cases of mastitis make other direct and simple methods of detection (e.g., milk stripping, udder visual inspection, palpation) more effective than an AHMS that is based on rumination and activity only. Nevertheless, rumination and activity or alert systems generated based on these parameters (e.g., HIS) could be used as tools for diagnosing severe cases of clinical mastitis caused by pathogens such as $E$. 
coli, which have profound systemic effects for the cow. Another potential application consists of using rumination and activity as markers of systemic compromise and as an aid in treatment decision-making, because changes in milk composition or udder status do not provide information about cows' overall health status.

From an on-farm implementation perspective, the HIS generated by the AHMS tested in our study could be used to detect severe cases of mastitis that affect the cow systemically. The use of HIS could be complemented by other parameters not reported in this study but generated based on rumination behavior and activity (e.g., weekly rumination and activity, deviations in the last $2 \mathrm{~h}$ ) that could be retrieved separately for individual cows or groups of cows. However, the most likely scenario is that not all cows that develop a case of mastitis will be detected. This is because the underlying health disorder does not compromise cow health sufficiently to dramatically reduce rumination and activity in all cows. Thus, it seems reasonable to suggest that for farms with proactive health-monitoring and treatment programs, the AHMS could be used in combination with other traditional methods of mastitis detection. The AHMS may be a valuable tool for providing further insights about the overall health status of the cow.

\section{CONCLUSIONS}

Our findings demonstrated that automated rumination and activity monitoring was effective for identifying cows with clinical cases of mastitis caused by E. coli and cases of mastitis concurrent with another health disorder. Conversely, the ability of the AHMS to identify cows with clinical mastitis caused by pathogens other than E. coli was moderate. Overall, cows with clinical mastitis were identified earlier than through CD by farm personnel. The patterns of rumination, activity, and HIS from -5 to $5 \mathrm{~d}$ after CD for cows with clinical mastitis were characterized by marked differences compared to cows in the ND group. Among cows with clinical mastitis, those not identified by HIS had rumination and activity patterns very similar to cows in the ND group and different from cows diagnosed with the disorder but flagged by HIS. We conclude that automated health-monitoring systems that use rumination and physical activity should be used in combination with or to complement traditional methods of mastitis detection. Future research is needed to evaluate the effect of management programs that combine rumination and activity monitoring with traditional methods to diagnose mastitis on cow well-being and performance.

\section{ACKNOWLEDGMENTS}

The authors extend their gratitude to the owners, managers, and personnel of the commercial dairy farm that participated in the study for providing access to their cows and facilities, and their collaboration with our research team. We also extend our gratitude to SCR Dairy (Madison, WI) for partial financial and logistical support to conduct this research and to Thomas Overton (Cornell University, Ithaca, NY) for providing useful feedback on the manuscript. Matias Stangaferro received partial support from a Fulbright fellowship and from Universidad Nacional del Litoral, Esperanza, Argentina.

\section{REFERENCES}

Ahmadzadeh, A., F. Frago, B. Shafii, J. Dalton, W. Price, and M. McGuire. 2009. Effect of clinical mastitis and other diseases on reproductive performance of Holstein cows. Anim. Reprod. Sci. 112:273-282.

Akers, R. M., and S. C. Nickerson. 2011. Mastitis and its impact on structure and function in the ruminant mammary gland. J. Mammary Gland Biol. Neoplasia 16:275-289.

Bar, D., Y. Gröhn, G. Bennett, R. González, J. Hertl, H. Schulte, L. Tauer, F. Welcome, and Y. Schukken. 2007. Effect of repeated episodes of generic clinical mastitis on milk yield in dairy cows. J. Dairy Sci. 90:4643-4653.

Bareille, N., F. Beaudeau, S. Billon, A. Robert, and P. Faverdin. 2003. Effects of health disorders on feed intake and milk production in dairy cows. Livest. Prod. Sci. 83:53-62.

Bradley, A. J., and M. Green. 2001. Aetiology of clinical mastitis in six Somerset dairy herds. Vet. Rec. 148:683-686.

Burvenich, C., D. D. Bannerman, J. Lippolis, L. Peelman, B. Nonnecke, M. Kehrli, and M. Paape. 2007. Cumulative physiological events influence the inflammatory response of the bovine udder to Escherichia coli infections during the transition period. J. Dairy Sci. 90(E-Suppl.):E39-E54.

Burvenich, C., V. Van Merris, J. Mehrzad, A. Diez-Fraile, and L. Duchateau. 2003. Severity of E. coli mastitis is mainly determined by cow factors. Vet. Res. 34:521-564.

Fitzpatrick, C. E., N. Chapinal, C. Petersson-Wolfe, T. DeVries, D. Kelton, T. Duffield, and K. Leslie. 2013. The effect of meloxicam on pain sensitivity, rumination time, and clinical signs in dairy cows with endotoxin-induced clinical mastitis. J. Dairy Sci. $96: 2847-2856$.

Fogsgaard, K. K., C. M. Røntved, P. Sørensen, and M. S. Herskin. 2012. Sickness behavior in dairy cows during Escherichia coli mastitis. J. Dairy Sci. 95:630-638.

Gröhn, Y. T., R. González, D. J. Wilson, J. Hertl, G. Bennett, H. Schulte, and Y. Schukken. 2005. Effect of pathogen-specific clinical mastitis on herd life in two New York State dairy herds. Prev. Vet. Med. 71:105-125.

Gröhn, Y. T., D. J. Wilson, R. González, J. Hertl, H. Schulte, G. Bennett, and Y. Schukken. 2004. Effect of pathogen-specific clinical mastitis on milk yield in dairy cows. J. Dairy Sci. 87:3358-3374.

Hailemariam, D., R. Mandal, F. Saleem, S. M. Dunn, D. S. Wishart, and B. N. Ametaj. 2014. Identification of predictive biomarkers of disease state in transition dairy cows. J. Dairy Sci. 97:2680-2693.

Harmon, R. J. 1994. Physiology of mastitis and factors affecting somatic cell counts. J. Dairy Sci. 77:2103-2112.

Hertl, J. A., Y. Gröhn, J. Leach, D. Bar, G. Bennett, R. Gonzalez, B. Rauch, F. Welcome, L. Tauer, and Y. Schukken. 2010. Effects of clinical mastitis caused by gram-positive and gram-negative bac- 
teria and other organisms on the probability of conception in New York State Holstein dairy cows. J. Dairy Sci. 93:1551-1560.

Hertl, J. A., Y. Schukken, D. Bar, G. Bennett, R. González, B. Rauch, F. Welcome, L. Tauer, and Y. Gröhn. 2011. The effect of recurrent episodes of clinical mastitis caused by gram-positive and gramnegative bacteria and other organisms on mortality and culling in Holstein dairy cows. J. Dairy Sci. 94:4863-4877.

Ingvartsen, K. L. 2006. Feeding-and management-related diseases in the transition cow: Physiological adaptations around calving and strategies to reduce feeding-related diseases. Anim. Feed Sci. Technol. 126:175-213.

Ingvartsen, K. L., R. Dewhurst, and N. Friggens. 2003. On the relationship between lactational performance and health: Is it yield or metabolic imbalance that cause production diseases in dairy cattle? A position paper. Livest. Prod. Sci. 83:277-308.

Kamphuis, C., D. Pietersma, R. Van der Tol, M. Wiedemann, and H. Hogeveen. 2008. Using sensor data patterns from an automatic milking system to develop predictive variables for classifying clinical mastitis and abnormal milk. Comput. Electron. Agric. 62:169181.

Kaneene, J. B., and H. S. Hurd. 1990. The National Animal Health Monitoring System in Michigan. III. Cost estimates of selected dairy cattle diseases. Prev. Vet. Med. 8:127-140.

Keefe, G. P. 1997. Streptococcus agalactiae mastitis: A review. Can. Vet. J. 38:429-437.

Koop, G., T. van Werven, S. Roffel, H. Hogeveen, K. Nazmi, and F. Bikker. 2015. Short communication: Protease activity measurement in milk as a diagnostic test for clinical mastitis in dairy cows. J. Dairy Sci.9846134618.

Nash, D. L., G. Rogers, J. Cooper, G. Hargrove, and J. F. Keown. 2002. Relationships among severity and duration of clinical mastitis and sire transmitting abilities for somatic cell score, udder type traits, productive life, and protein yield. J. Dairy Sci. 85:1273-1284.

Nikolić, J. A., M. Kulcsár, L. Kátai, O. Nedić, S. Jánosi, and G. Huszenicza. 2003. Periparturient endocrine and metabolic changes in healthy cows and in cows affected by mastitis. J. Vet. Med. A Physiol. Pathol. Clin. Med. 50:22-29.

Østerås, O., H. Solbu, A. Refsdal, T. Roalkvam, O. Filseth, and A. Minsaas. 2007. Results and evaluation of thirty years of health recordings in the Norwegian dairy cattle population. J. Dairy Sci. 90:4483-4497.

Radostits, O. M., C. C. Gay, K. W. Hinchcliff, and P. D. Constable. 2006. Veterinary Medicine: A Textbook of the Diseases of Cattle, Horses, Sheep, Pigs and Goats. Elsevier Health Sciences, Philadelphia, PA.

Santos, J. E., R. Cerri, M. Ballou, G. Higginbotham, and J. Kirk. 2004. Effect of timing of first clinical mastitis occurrence on lacta- tional and reproductive performance of Holstein dairy cows. Anim. Reprod. Sci. 80:31-45.

Sargeant, J. M., H. M. Scott, K. E. Leslie, M. J. Ireland, and A. Bashiri. 1998. Clinical mastitis in dairy cattle in Ontario: Frequency of occurrence and bacteriological isolates. Can. Vet. J. 39:33-38.

Schukken, Y. H., J. Hertl, D. Bar, G. Bennett, R. González, B. Rauch, C. Santisteban, H. Schulte, L. Tauer, and F. Welcome. 2009. Effects of repeated gram-positive and gram-negative clinical mastitis episodes on milk yield loss in Holstein dairy cows. J. Dairy Sci. 92:3091-3105.

Schukken, Y. H., J. Günther, J. Fitzpatrick, M. Fontaine, L. Goetze, O. Holst, J. Leigh, W. Petzl, H.-J. Schuberth, and A. Sipka. 2011. Host-response patterns of intramammary infections in dairy cows. Vet. Immunol. Immunopathol. 144:270-289.

Siivonen, J., S. Taponen, M. Hovinen, M. Pastell, B. J. Lensink, S. Pyörälä, and L. Hänninen. 2011. Impact of acute clinical mastitis on cow behaviour. Appl. Anim. Behav. Sci. 132:101-106.

Sørensen, L. P., M. Bjerring, and P. Løvendahl. 2016. Monitoring individual cow udder health in automated milking systems using online somatic cell counts. J. Dairy Sci. 99:608-620.

Stangaferro, M. L., R. Wijma, L. S. Caixeta, M. A. Al-Abri, and J. O. Giordano. 2016. Use of rumination and activity monitoring for the identification of dairy cows with health disorders. Part I. Metabolic and digestive disorders. J. Dairy Sci. 99:7395-7410. http:// dx.doi.org/10.3168/jds.2016-10907.

Todhunter, D. A., K. Smith, and J. Hogan. 1995. Environmental streptococcal intramammary infections of the bovine mammary gland. J. Dairy Sci. 78:2366-2374.

Van Winden, S. C. L., R. Jorritsma, K. E. Müller, and J. P. T. M. Noordhuizen. 2003. Feed intake, milk yield, and metabolic parameters prior to left displaced abomasum in dairy cows. J. Dairy Sci. $86: 1465-1471$.

Wenz, J. R., F. B. Garry, and G. M. Barrington. 2006. Comparison of disease severity scoring systems for dairy cattle with acute coliform mastitis. J. Am. Vet. Med. Assoc. 229:259-262.

Whist, A. C., O. Østerås, and L. Sølverød. 2009. Association between isolation of Staphylococcus aureus one week after calving and milk yield, somatic cell count, clinical mastitis, and culling through the remaining lactation. J. Dairy Res. 76:24-35.

White, L. J., Y. H. Schukken, B. Dogan, L. Green, D. Döpfer, M. J. Chappell, and G. F. Medley. 2010. Modelling the dynamics of intramammary E. coli infections in dairy cows: Understanding mechanisms that distinguish transient from persistent infections. Vet. Res. 41:13.

Zhao, X., and P. Lacasse. 2008. Mammary tissue damage during bovine mastitis: Causes and control. J. Anim. Sci. 86(13 Suppl.):57-65. 